\title{
25 Research Square \\ Depth distribution of belowground net primary production across global biomes
}

Zhongkui Luo ( $\square$ luozk@zju.edu.cn )

Zhejiang University https://orcid.org/0000-0002-6744-6491

Guocheng Wang

Chinese Academy of Sciences https://orcid.org/0000-0002-4141-4395

\section{Liujun Xiao}

Zhejiang University

\section{Xiali Mao}

Zhejiang University

\section{Xiaowei Guo}

Zhejiang University

\section{Annette Cowie}

University of New England https://orcid.org/0000-0002-3858-959X

\section{Shuai Zhang}

Zhejiang University

\section{Mingming Wang}

Zhejiang University

\section{Songchao Chen}

INRAE Unité InfoSol

\section{Ganlin Zhang}

Institute of Soil Science, Chinese Academy of Sciences

\section{Zhou Shi}

\section{Zhejiang University}

\section{Research Article}

Keywords: Plant root-derived carbon (C), mineral bulk soil, soil C dynamics, net primary production

Posted Date: May 12th, 2021

DOl: https://doi.org/10.21203/rs.3.rs-65178/v2

License: (9) This work is licensed under a Creative Commons Attribution 4.0 International License. Read Full License 


\section{Abstract}

The depth distribution of belowground net primary production (BNPP) has been unquantified globally, hindering our understanding of belowground carbon dynamics. We synthesize global observational data sets to infer the depth allocation of BNPP down to $2 \mathrm{~m}$, and map depth-specific BNPP globally at $1 \mathrm{~km}$ resolution. We estimate that global average BNPP in the $0-20$ soil layer is $1.1 \mathrm{MgC} \mathrm{ha}^{-1} \mathrm{yr}^{-1}$, accounting for $>50 \%$ of total BNPP. Across the globe, the depth distribution of BNPP shows large variability, and more BNPP is allocated to deeper layers in hotter and drier regions. Edaphic, climatic and topographic properties (in the order of importance) can explain $>80 \%$ of such variability in different soil depths; and the direction and magnitude of the influence of individual properties (e.g., precipitation and soil nutrient) are soil depth- and biome-dependent. Our results provide global benchmarks for predictions of whole-soil carbon profiles across global biomes.

\section{Introduction}

Plant net primary production (NPP) is a fundamental ecosystem property, providing food, energy and fiber for higher trophic organisms, and mediating the global carbon cycle by linking atmospheric and soil carbon reservoirs (1-3). In mineral soils - the largest terrestrial carbon reservoir (4), belowground NPP (BNPP) is the predominant source of soil carbon and its depth distribution is critical for understanding whole-soil profile carbon dynamics. On the one hand, the vertical distribution of BNPP couples with a series of belowground processes such as plant water uptake and nutrient acquisition, microbial and soil fauna activities which are important processes modulating soil carbon turnover behaviors in different soil layer depths (5). On the other hand, BNPP represents the major new carbon inputs to different soil depths, together with carbon outputs mainly through the respiration of soil microorganisms, determining soil carbon balance in soil depths (6). The new carbon may actively interact with bulk soil old carbon via the priming effect (i.e., new carbon promotes or retards native carbon decomposition in the bulk soil) $(7,8)$, regulating soil carbon stability (9). Overall, it is vital to quantify the depth distribution of BNPP to elucidate belowground processes and making reliable depth-specific predictions of soil carbon and relevant biogeochemical cycles (e.g., nutrients) in the soil profile.

The BNPP can be reasonably estimated by root growth measurements (10-12) or using state-of-the-art tracer (e.g., carbon isotopes) techniques (13). Data synthesis based on BNPP measurements enables us to rigorously address questions relating to soil carbon dynamics at large spatial scales such as carbon turnover times based on the ratio of soil carbon stocks to $\operatorname{BNPP}(6,14)$. Indeed, by synthesizing field measurements of aboveground NPP (ANPP), combining with satellite-derived NPP, total BNPP (i.e., satellite-derived NPP - ANPP) has been quantified at a global scale (15). Nevertheless, the vertical distribution of BNPP in the soil profile remains unexplored, especially across large extents, due to technical challenges in un-destructively measuring belowground carbon budgets depth by depth in situ (16). Moreover, factors controlling BNPP and particularly its depth distribution may be diverse and vary across space $(17,18)$, resulting in the difficulty to construct unified models to accurately estimate the depth distribution of BNPP. In Earth system models, for example, BNPP and its depth distribution are 
usually assumed to be a constant fraction of total NPP. The fraction only varies with plant functional types; and climate is generally considered to be the dominant determinant $(19,20)$. This simplification of controls over BNPP would be the major source of the uncertainty in predictions of climate-carbon cycle feedbacks as well as belowground processes such as soil carbon sequestration potential over space and time (21). We need an advanced understanding of whether and how soil depth-specific BNPP (i.e., the vertical distribution of BNPP) is modulated by environmental factors such as edaphic and topographic attributes.

This study builds upon the ORNL DAAC legacy global data set of field NPP measurements with the partitioning of aboveground and belowground fractions (i.e., ORNL DAAC data set, https://daac.ornl.gov/cgi-bin/dataset_lister.pl?p=13). We further update this data set by searching data from peer-reviewed literature (i.e., literature-derived data set). At last, we have obtained 725 soil profiles $\left(\right.$ NPP $_{\text {obs }}$ hereafter which includes 367 and 358 profiles in the ORNL DAAC and literature-derived data sets, respectively) across the globe which enable us to estimate above- and below-ground NPP (Figs. 1a and S1a). It should be noted that the ORNL DAAC data set is quality-contronlled in order to minimize the potential effects of different measurement techniques on the estimation of NPP and its allocation. Although the potential discrepancies in measurement techniques, we find that overall the ORNL DAAC and literature-derived data sets do not show significant differences in terms of belowground NPP (BNPP) estimates except in several specific biomes (Fig. S1b). In addition, the two data sets present a very similar latitudinal pattern of BNPP and are complementary in terms of both spatial (Fig. S1a) and latitudinal coverage (Fig. S1C). In this study, we pool all data together to amplify the usage of the two valuable data sets and the underlying consequences are quantified by uncertainty assessment.

Combining the NPP ${ }_{\text {obs }}$ data set with another data set of the vertical distribution of root biomass in 559 soil profiles (Root ${ }_{\text {obs }}$ hereafter; Fig. 1a and Table S1), we estimate the allocation of BNPP to seven sequential soil layers (i.e., 0-20, 20-40, 40-60, 60-80, 80-100, 100-150, and 150-200 cm) by assuming that BNPP depth allocation is proportional to root biomass distribution in soil profile. Using a suite of environmental covariates including climatic, edaphic and topographic properties (Table S2), we assess the underlying drivers regulating the depth distribution of BNPP across the globe as well as in different biome types. Machine learning-based models are developed to map the depth distribution of BNPP and its uncertainty across the globe at the resolution of $0.0083^{\circ}$ (which is equivalent to approximately $1 \mathrm{~km}$ at the equator).

\section{Results}

The total amount of BNPP

Averaging across the $725 \mathrm{NPP}_{\text {obs }}$ soil profiles (Fig. 1a), BNPP in the $0-200 \mathrm{~cm}$ soil profile is ${ }^{3.28_{0.19}^{12.0}} \mathrm{Mg} \mathrm{ha}^{-}$ ${ }^{1} \mathrm{yr}^{-1}$ (mean with $2.5 \%$ and $97.5 \%$ quantiles, Fig. 1b). BNPP is significantly different among biomes $(P<$ 0.05; Fig. 1b). Mediterranean/montane shrublands have the highest BNPP (5.49:15.2 $\left.\mathrm{Mg} \mathrm{ha}^{-1} \mathrm{yr}^{-1}\right)$, followed by croplands (4.421.0.5 $\mathrm{Mg} \mathrm{ha}^{-1} \mathrm{yr}^{-1}$ ) and tropical/subtropical forests ( $\left(4.29_{13.3}^{1.2} \mathrm{Mg} \mathrm{ha}^{-1} \mathrm{yr}^{-1}\right.$ ); and tundra has 
the lowest ( $0.90_{3.41}^{0.21} \mathrm{Mg} \mathrm{ha}^{-1} \mathrm{yr}^{-1}$; Fig. 1 b). The proportion of BNPP to total NPP (i.e., $f_{B N P P}$ ) is $388 \%$, with significant difference among biomes (Fig. 1C). It is on average greater than $50 \%$ in arid or semi-arid environments such as temperate grasslands and deserts, but only $30 \%$ in tropical/subtropical, temperate and boreal forests (Fig. 1c).

\section{The depth distribution of BNPP}

Using root profiles (i.e., the Root $_{\text {obs }}$ data set) to infer the proportional depth distribution (PDD, unit in \%) of BNPP in the seven soil layers, the results indicate that on average roughly $60 \%$ of BNPP is allocated to the 0-20 cm soil layer (Fig. 2a); and the top $40 \mathrm{~cm}$ soil layer holds around $80 \%$ of BNPP (Fig. 2a). In other deeper soil layers, BNPP allocation is relatively small and shows much less variance than in upper layers (Fig. 2a). In the top $20 \mathrm{~cm}$ soil layer, for example, the proportional allocation of BNPP ranges from $37 \%$ (2.5\% quantile) to $78 \%$ (97.5\% quantile). For proportional BNPP allocation to a typical soil layer, it is significantly $(P<0.05)$ different among biomes (Fig. 2c). Boreal forests and tundra relatively allocate more ( $70 \%$ of BNPP) to upper layers (e.g., $0-20 \mathrm{~cm}$ ) than other biome types (e.g., $<50 \%$ in tropical/subtropical grasslands/savannas and deserts which allocate more BNPP to deeper layer depths, Fig.2c).

Because the locations of $\mathrm{NPP}_{\text {obs }}$ soil profiles do not match with that of $\operatorname{Root}_{\mathrm{obs}}$ (Fig. 1a), we develop

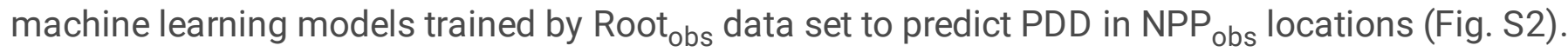
Multiplying the observed BNPP at NPP ${ }_{\text {obs }}$ locations by PDD predictions, the absolute amount of BNPP in the seven soil layers is estimated with the consideration of prediction uncertainties by the model. As the PDD (Fig. 2a), the absolute amount of BNPP also decreases exponentially with soil depths, with greater variances in upper soil layers than in deeper layers. Across the globe, an average BNPP of $1.60 \mathrm{Mg} \mathrm{ha}^{-1}$ $\mathrm{yr}^{-1}$ is estimated in the top $20 \mathrm{~cm}$ soil (Fig. 2b). In the $20-40 \mathrm{~cm}$ soil layer, the average BNPP is reduced to $0.69 \mathrm{Mg} \mathrm{ha}^{-1} \mathrm{yr}^{-1}$. In deeper layers, BNPP is relatively small and comparable ( $\left.<0.30 \mathrm{Mg} \mathrm{ha}^{-1} \mathrm{yr}^{-1}\right)$ with smaller variances (Fig. 2b). Among biomes, the absolute BNPP shows significant disparities (Fig. 2d). In the top layers (e.g., 0-20 cm), higher BNPP is observed in Mediterranean/Montane shrublands (2.37 $\left.\mathrm{Mg} \mathrm{ha}^{-1} \mathrm{yr}^{-1}\right)$ and temperate forests $\left(2.11 \mathrm{Mg} \mathrm{ha}^{-1} \mathrm{yr}^{-1}\right)$ than in boreal forests $\left(0.94 \mathrm{Mg} \mathrm{ha}^{-1} \mathrm{yr}^{-1}\right)$ and tundra $\left(0.52 \mathrm{Mg} \mathrm{ha}^{-1} \mathrm{yr}^{-1}\right)$. In deeper soil layers, the variations in absolute BNPP among biomes are in general consistent with those in the top $0-20 \mathrm{~cm}$ soil (Fig. 2d).

\section{Drivers of BNPP allocation}

As might be expected, soil depth is the most important predictor for the depth distribution of BNPP (Fig. $3 a$ and b). An exponential model using depth as the only predictor can explain $23-56 \%$ of the variance in the depth distribution of BNPP across the globe $\left(R^{2}=0.34\right)$ and in different biome types $\left(R^{2}\right.$ ranges from 0.23 to 0.56 ; Fig. 3a, Table S3). The coefficients of the exponential model indicating BNPP allocated to the top layer and decreasing rate of BNPP with soil depth are significantly different among biomes (Table S3), further demonstrating that the depth distribution of BNPP is significantly different among biomes (Fig. 2). 
A random forest model taking into account soil depth, biome type and additional 55 environmental covariates (Table S2), after controlling multicollinearity among the covariates (Figs. S3, S4), can explain $92 \%\left(R^{2}=0.92\right)$ of the variance in the depth distribution of BNPP in the whole $0-200 \mathrm{~cm}$ soil profile across the globe (Fig. 3b). Following soil depth, MAT (mean annual temperature, which is shown as BIO1 in the figure), AE (mean actual daily soil evaporation), biome type, BD (soil bulk density) and MAP (mean annual precipitation, BIO12) are the most important five predictors (Fig. 3b). Grouping the environmental predictors into climatic (temperature- and precipitation-related, a total of 7 variables in the model), edaphic (12 variables) and topographic (7 variables) ones, the result indicates that the contributions of climate, soil and topography are $26 \%, 28 \%, 13 \%$ (Table S4). Focusing on BNPP in specific soil layer depths, the fitted random forest models can explain over $80 \%$ of BNPP variances in each of the seven soil layers (Fig. S5). MAT is consistently the most important factor, followed by AE, MAP, soil carbon:nitrogen ratio (i.e., SCN) in deeper layers (Fig. 3b; Fig. S5). In terms of the overall influence of climatic, edaphic and topographic variables, climatic variables together contribute $33-40 \%$ depending on soil layer depths; and edaphic and topographic properties contribute $33-40 \%$ and $18-28 \%$, respectively (Figs. 3b, S5; Table S4).

Besides the relative importance of various environmental variables identified by the random forest models, linear mixed-effects modelling is further conducted to identify the direction and magnitude of their first-order relationship with BNPP depth allocation (Fig. 3c). As expected, BNPP depth allocation is negatively correlated to soil depth (Fig. 3c). In general, the effects of all climate-related variables are positive; while the effects of soil-related variables are negative except the positive effects of $A E$ and soil carbon to nitrogen ratio. In different biomes, however, the magnitude and, in some cases, the direction of the regression coefficient are substantially different (Fig. 3c). For example, MAT (i.e., BI01) has a positive effect in most biomes, but its effect is negative in tropical/subtropical grasslands/savannas. Overall, the varying regression coefficients of the predictor variables in terms of both magnitude and direction among biome types (Fig. 3c) indicate that the effects of environmental controls are biome-dependent. However, it should be noted that the first-order effects of all variables on BNPP are relatively weak at the global scale albeit significant (Figs. 3c and S6). A partial correlation analysis controlling the effect of soil depth is also conducted to assess whether the effects of soil-, climate- and topography-related variables are modulated by soil depth. The results of the zero-order correlations between BNPP and the assessed predictors are generally consistent with the results of the mixed-effects regression (Fig. 3c vs Fig. S6a). After controlling the effect of soil depth by conducting a partial correlation analysis, however, most correlation coefficients have been changed, particularly the correlations with soil properties (Fig. S6b,c) which suggest that the effects of soil properties are depth-dependent.

\section{Global pattern of the depth distribution of BNPP}

The depth distribution of BNPP is mapped across the globe at the $0.0083^{\circ}$ resolution (which is equal to $\sim 1 \mathrm{~km}$ at the equator; Fig. 4). Using the NPP ${ }_{\text {obs }}$ data set, machine learning-based models are first developed to predict BNPP (Fig. S7). Combining with models for estimating the proportional depth distribution of BNPP (PDD, Fig. S2), then BNPP in each $1 \mathrm{~km}$ grid and each of the seven depths is estimated (i.e., BNPP $\times$ PDD) taking into account uncertainties in the estimation of both BNPP and PDD 
(Fig. 4). Across the globe, BNPP in the $0-200 \mathrm{~cm}$ soil profile is $2.00_{0.41}^{3.05} \mathrm{Mg} \mathrm{ha}^{-1} \mathrm{yr}^{-1}$ (Figs. 4, 5a). The largest BNPP on average occurs in $\sim 20^{\circ} \mathrm{N}$ (Fig. 5a). In all soil layers, it is general that BNPP is relatively low in desert and northern Hemisphere high latitudinal regions (Fig. 4) with an apparent decreasing trend from $40^{\circ} \mathrm{N}$ to $80^{\circ} \mathrm{N}$ (Fig. 5a). The highest BNPP is in tropical/subtropical forests, temperate forests and croplands; and the lowest in tundra, boreal forests and deserts (Fig. 4). For the proportional depth distribution, averaging across the globe, it is $57 \%$ and $77 \%$ in the top 20 and $40 \mathrm{~cm}$ soil layers, respectively (Fig. 5b). With increasing latitudes from $40^{\circ} \mathrm{N}$ to $80^{\circ} \mathrm{N}$, more BNPP is allocated to upper soil layers (Fig. 5b). Fig. 6 shows the uncertainty (i.e., coefficient of variance in each $1 \mathrm{~km}$ grid) in predicted depth-specific BNPP. The uncertainty is greater in deeper soil layers, particularly in the northern Hemisphere high latitudinal regions such as tundra and boreal forests. Indeed, the uncertainty is markedly higher in tundra and boreal forests than in other biomes in deeper soil layers. Across the globe, the average uncertainty in the top $20 \mathrm{~cm}$ layer is $0.48_{0.72}^{0.27}$, and increased to $1.90_{4.28}^{0.89}$ in the $150-200 \mathrm{~cm}$ layer, respectively (Fig. 6).

\section{Discussion}

Using root biomass distribution to infer depth distribution of BNPP, we generated field observational dataderived global maps of BNPP down to $200 \mathrm{~cm}$ at a resolution of $\sim 1 \mathrm{~km}$. In the 0-200 cm soil profile, the global average BNPP is estimated to be $\sim 2 \mathrm{Mg} \mathrm{ha}^{-1} \mathrm{yr}^{-1}$ with a global total BNPP of $\sim 21 \mathrm{Pg} \mathrm{yr}^{-1}$. This estimate is close to the value of $2.2 \mathrm{Mg} \mathrm{ha}^{-1} \mathrm{yr}^{-1}$ (with a global total BNPP of $24.7 \mathrm{Pg} \mathrm{yr}^{-1}$ ) by Gherardi and Sala (15) who estimated total BNPP as the difference between satellite-derived NPP and field measurements of aboveground NPP. According to our data of $f_{B N P P}, f_{B N P P}$ is estimated to be $39 \%$ which is slightly lower than the estimation of $46 \%$ by Gherardi and Sala (15).

Our results further suggest that the majority of total BNPP ( $>50 \%)$ is allocated to the top $20 \mathrm{~cm}$ soil layer, and additional $\sim 20 \%$ to the $20-40 \mathrm{~cm}$ soil layer. This is consistent with a series of studies with field observations of BNPP depth distribution at individual sites across the globe (22-24). Among biomes, however, the depth distribution of BNPP is significantly different. Generally, more BNPP is allocated to deeper layers in drier biomes (e.g., deserts and grasslands). This may due to the close coupling of plant root growth with soil moisture profile $(25,26)$. More assimilated carbon would be allocated to deeper soil layers in drier environments to acquire water $(27,28)$. A synthesis of literature data has found that tropical grasslands/ savannas and deserts have the deepest rooting depth compared with other biomes (29). There is also a clear pattern of higher allocation of BNPP to upper layers in higher latitudes. Due to low temperature in high latitudinal regions, deep soil permafrost (e.g., in tundra) exists even in growing season, which inhibits root growth into the subsoil (29-31), resulting in a large fraction of BNPP allocated to surface layers. As biome type is inherently determined by climate conditions, it is reasonable to expect that climatic factors would play a key role in regulating BNPP depth distribution.

Indeed, climatic variables have significant effects on BNPP and its depth distribution. Mean annual temperature (MAT) and mean annual precipitation (MAP) are identified amongst the most important. MAP is the predominant, if not the only for most soils, source of soil moisture; while MAT determines the 
loss rate of soil moisture via evaporation and plant transpiration and the depth of active layer above the permafrost. Previous assessments at broad scales mainly focused on MAT and MAP, and have demonstrated the importance of these two climatic variables $(15,32-34)$. Our result further confirms that the climatic control is general on BNPP allocation in different soil layer depths. However, the linear mixedeffects regression indicates that the degree and even the direction of the correlation of BNPP with MAT and MAP are biome-dependent (Figs. $3 \mathrm{c}$ and S6). This may attribute to the differential responses of biomes to temperature and precipitation shifts depending on plant functional types and carbon allocation strategies $(35,36)$. For example, the growth of tropical species is more vulnerable to high temperature or drought than temperate or boreal trees. High temperature in humid ecosystems may induce more frequent drought or wildfire which deplete soil moisture in the top soil layer (37-39), resulting in stimulated root growth and/or deeper rooting to obtaining moisture. For MAT, its effect is positive in most biomes but negative in tropical/subtropical grasslands/savannas, which may relate to the shift from tree(which has deep rooting depth) to grass-dominant vegetation (which has relatively shallow rooting depth) with increasing MAT. Intriguingly, the general positive effect of both MAP and MAT is strongest in tundra. Warming experiments across the tundra biome have found that warming stimulates the growth of deciduous shrubs and graminoids and retards the growth of mosses and lichens (40), while former species have much deeper rooting depth and thus higher BNPP. A simulation study using the dynamic tundra vegetation model has reported that increasing precipitation under climate change benefits graminoids outcompeting shrubs, resulting in more root biomass in deeper soils as graminoids have higher rooting depth than shrubs (41). The tundra biome may be particularly sensitive to climate change in terms of BNPP allocation and the relevant soil processes.

Except for MAT and MAP, other climatic variables indicating climate seasonality and inter-annual variability also play a role in regulating BNPP allocation. Mean temperature diurnal range (i.e., BIO2) and mean temperature of the wettest quarter (i.e., BI08) are the most important climatic variables after MAT and MAP (Figs. 3b and S5). Overall, these results suggest that both the mean and variability of climatic conditions are important determinants of BNPP and its depth distribution; and, more importantly, the direction and magnitude of their effects are biome-specific probably depending on local plant functional types and their response to soil water dynamic regimes. Future climate (e.g., warming and precipitation change) and land cover changes (e.g., vegetation shift) may significantly alter the amount of carbon allocated to different soil layer depths thereby potentially modifying soil profile biogeochemical processes regulated by fresh carbon inputs.

Despite the leading role of climate, soil properties also play a vital role in cotrolling BNPP depth distribution. Indeed, mean actual daily soil evaporation (which is affected by both soil properties and climate conditions) is as important as MAT and MAP positively associating with BNPP, in line with the findings in global grasslands (34). A major reason would be that high soil evaporation means a higher probability of water stress, given otherwise similar to other environmental conditions. Soil carbon to nitrogen ratio also exerts significant positive effect, particularly in deeper layers (Fig. 3b, c). High soil carbon to nitrogen ratio may indicate poor nutrient availability in the soil. In nutrient-pool soils, the plant would have to invest more assimilated carbon to root growth for nutrient acquisition in deeper layers (10). 
Together with the general positive relationship between BNPP and climatic variables, these results reflect the key role of energy (e.g., temperature) and soil resource profiles (e.g., water and nitrogen) in regulating BNPP depth allocation. Other soil properties also cannot be ignored. For example, both soil bulk density and sand show negative effects on BNPP. They are key soil physical parameters determining the suitability of the soil environment for root growth (42). Another noteworthy phenomenon is that the effect of a typical soil property is soil layer-dependent, while the dependence of the effects of climatic and topographic variables is much weaker (Fig. S6c). These results demonstrate that depth distribution of BNPP is driven by complex interplay among edaphic, climatic and topographic variables, which is further modulated by biome type as different biomes may adopt distinct BNPP allocation strategies $(16,43,44)$.

The data used in this study builds upon quality-checked legacy data sets, and we further update the data via literature synthesis to generate a more comprehensive one that improves spatial coverage and benefits robust assessment at the global scale. Although we show evidence that the two data sets are not statistically different in terms of BNPP estimates (derived from peer-reviewed publications vs the ORNL DAAC legacy data; Fig. S1), we note several limitations in the estimation of BNPP depth allocation due to the difficulty in field measurements and adopted assumptions $(45,46)$. First, not all data include all BNPP components such as root exudates. BNPP allocated to root exudates and mycorrhizae may account for a significant fraction of BNPP (particularly in forest systems), but is challenging to measure in the field (45, 47). As such, BNPP in the data would be an underestimation of real BNPP and depend on the approach used to measure BNPP in specific studies. We do not explicitly distinguish measurement techniques and the underlying consequences on the estimation of BNPP. Second, most data only include BNPP in a single year, but BNPP would present inter-annual variability. Given that we focus on the spatial variability of BNPP across the globe, however, the consequences of temporal variability on our estimates would be small if we accept that inter-annual variability is smaller than spatial variability. This also can be evidenced by the comparable estimates of global BNPP in this study to that by Gherardi and Sala (15) in which the temporal variability of BNPP is considered. Third, our approach implicitly assumes that roots in different soil depths have the same turnover times. For some plants, roots in different soil layers (e.g., coarse vs fine roots) may have different functions, and roots with different functions may distribute unequally in soil layer depths $(31,48)$. Thus, turnover times of different root functional types may be different, resulting in biases in the estimation of the proportional depth distribution of BNPP acrodding to root biomass alone.

BNPP and its depth distribution are the least constrained component of the global carbon budget (49). To our knowledge, we are the first to spatially, explicitly predict depth-specific BNPP allocation across the globe with the quantification of prediction uncertainties. The quantitative information is critical for explicit representation of soil layer-specific carbon inputs. By quantifying the spatial pattern of BNPP depth distribution, our maps provide the information on plant carbon allocation that can be potentially used to promote their application across large extents at resolutions meaningful for land management. The maps also can be used to parameterize, scale or benchmark spatially explicit model predictions of carbon allocation and thus facilitate simulation of soil carbon turnover and dynamics. 


\section{Materials And Methods}

To quantify the depth distribution of BNPP across the globe, we integrated observational global datasets, including NPP datasets of field observations of aboveground and belowground fractions (NPP $\left.{ }_{\text {obs }}\right)$ and root biomass ( Root $_{\text {obs }}$ ) in the soil profile. In general, the data sets span across the globe (Fig. 1a) covering various climatic, edaphic and topographic conditions. We also used soil, climate, and topography databases along with biome types and soil order to obtain environmental covariates (edaphic, climatic, topographical variables; Table. S1). Combing these environmental covariates with $\mathrm{NPP}_{\text {obs }}$ and Root $_{\mathrm{obs}}$ we developed models to predict the depth distribution of BNPP, identify its drivers, and map it across the globe.

Data acquisition. We collected field net primary production (NPP) data from 725 soil profiles (Fig. 1a;

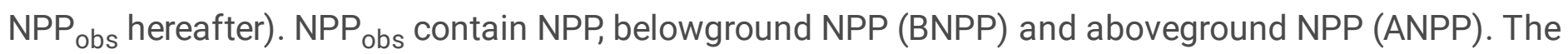
dataset was compiled by a thorough literature search and data synthesis from 54 published peerreviewed papers (Supplementary references) and the ORNL DAAC NPP data collection (https://daac.ornl.gov/cgi-bin/dataset_lister.pl?p=13). We obtained root biomass and its depth distribution from 559 soil profiles to infer the depth distribution of BNPP (see the section Estimation of the depth distribution of BNPP). The root biomass data set (Root $\left.{ }_{\mathrm{obs}}\right)$ was originally compiled by Schenk and Jackson (50).

We obtained a set of global layers of environmental covariates including soil properties, climate, topography and biome type (Table S1) as potential predictor variables of BNPP and its depth distribution. A total of 20 soil physical and chemical properties (Table S2) were obtained from ISRIC-WISE soil profile database (4) with a spatial resolution of $1 \mathrm{~km}$. We obtained 19 climatic attributes with the same resolution as the WISE database from WorldClim (51), which quantifies biologically meaningful variables using monthly temperature and precipitation. Actual soil evaporation (AE) counted as the liquid water supply plus the soil water utilized was obtained from TerraClimate (52). In addition, we derived spatial layers of biome type by aggregating two land cover maps (i.e., the MODIS land cover map (53) and the Terrestrial Ecoregions of the World (54)) to generate a map consisting of nine biome types. Finally, we calculated 13 topographic attributes from SRTM-DEM at $90 \mathrm{~m}$ resolution (http://srtm.csi.cgiar.org) using 'elevatr', 'spatialEco' and 'dynatopmodel' packages in R 3.6.1 (55) and SAGA (56). More details of these global spatial covariate layers are given in Table S1.

Estimation of the depth distribution of BNPP. Total BNPP has been recorded in the NPP ${ }_{\text {obs }}$ data set. To quantify BNPP allocated to different soil layer depths, the most straightforward way is to directly measure BNPP in different soil layers. However, no sites have such measurement with BNPP in the $\mathrm{NPP}_{\text {obs }}$ data set. In this study, we assume that BNPP allocated to a specific layer is proportional to root biomass in that layer. Using the Root ${ }_{\text {obs }}$ data set, we calculated the depth distribution of root biomass in seven sequential layers in the $0-200 \mathrm{~cm}$ soil profile (i.e., 0-20, 20-40, 40-60, 60-80, 80-100, 100-150 and $150-200 \mathrm{~cm})$, using the following equations $(6,50)$ : 
$r_{D}=\frac{R_{\max }}{1+\left(\frac{D}{D_{50}}\right)^{c}}$,

where $r_{D}$ is the total root biomass above soil depth $D(\mathrm{~cm}), R_{\max }$ is the total root biomass in the soil profile, $D_{50}$ is the depth $(\mathrm{cm})$ at which $r_{D}$ is $50 \%$ of $R_{\max }$ and $c$ is a shape parameter optimized by the Root $_{\text {obs }}$ data set (50):

$$
c=\frac{-1.27875}{\log _{10} D_{95}-\log _{10} D_{50}},
$$

where $D_{95}$ is the depth (cm) at which $r_{D}$ is $95 \%$ of $R_{\max }$. According to Eq. (1), the fraction $\left(f_{\text {root }}\right)$ of roots in any soil layer depths such as the $20-40 \mathrm{~cm}$ soil layer depth can be estimated as:

$$
f_{\text {root }, 20-40}=\frac{r_{40}}{r_{\max }}-\frac{r_{20}}{r_{\max }}=\frac{1}{1+\left(\frac{40}{D_{50}}\right)^{c}}-\frac{1}{1+\left(\frac{20}{D_{50}}\right)^{c}}
$$

The Root ${ }_{\text {obs }}$ had been used to interpolate $D_{50}$ and $D_{95}(6,50)$, which have been adopted in this study. Based on the Root ${ }_{\text {obs }}$-derived proportional depth distribution of roots (i.e., $f_{\text {root }}$ ), we train a machine learning-based model to predict the proportional depth distribution of BNPP at NPP obs sites. Then, BNPP in a typical layer such as $20-40 \mathrm{~cm}$ can be estimated as BNPP multiplied by the proportion of total BNPP in that layer.

Drivers of BNPP depth allocation. We performed a machine learning-based statistical model - random forest (RF) and linear mixed-effect regression to explore environmental drivers of BNPP depth distribution. Before fitting the models, variance inflation factor (VIF) was calculated and used to minimize the multicollinearity of environmental covariates. The environmental variables with a VIF value larger than 10 were eliminated in the assessment (Fig. S5). To examine how well the data spread throughout the multivariate environmental covariate space and further reduce the dimension of the data, we perform a multiple factor analysis (MFA) using R package 'FactoMineR', which takes into account the contribution of all active groups of variables to define the distance between individual variables. We then standardize all selected explanatory variables and transform the composite image into the same MFA spaces. The first eight principal components explained more than $80 \%$ of the sample space variation, and the group of climate contributes most to the space variation in the first principal component (Fig. S3). To determine the relative importance of the environmental factors, we calculated the relative contribution of predictor variables to the explained variance (i.e., relative importance) by the model using importance scores for each predictor in the RF model. Because the RF algorithm inherently performs bagging and random selection of explanatory variables and calculates the out-of-bag error for feature ranking, 500 bootstrap draws from total input data are applied to quantify the uncertainties in the estimated relative contributions. These assessments were conducted using packages 'ranger' and 'caret' in the R software (R Core Team, 2020). 
Linear mixed-effects models (using the 'Imer' function of the 'ImerTest' package in R) were performed to further identify the correlations between BNPP depth allocation and the individually selected environmental covariates, and investigate whether and how biome type regulates those correlations by treating biome type as the random effect factor. In addition, we conducted correlation analysis to evaluate the general relationship between selected controlling factors (i.e., the most important ones) and depth distribution of BNPP. Partial correlation was also conducted to assess that whether the correlations between BNPP and environmental predictors are soil depth-dependent by controlling the effect of soil depth.

Global mapping and prediction uncertainty. We explored machine-learning-based models, including random forest (RF), extreme gradient boosting (XGBoost), Cubist, support vector machines (SVM), bayesian regularized artificial neural networks (BRANNs) and lasso regression (LASSO), and selected the

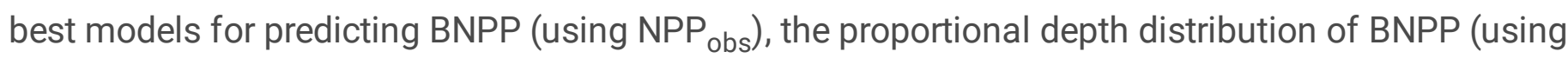

Root $_{\mathrm{obs}}$ ) across the globe. For each model, the selected environmental covariates after minimizing multicollinearity via VIF selection and MFA dimensionality reduction were used; $80 \%$ soil profiles were randomly selected for training and the remaining $20 \%$ for validation. A 'tuneGrid' method (R package 'caret') was used to compute model performance metric (i.e., rooted mean squared error-RMSE) for a set of tuning hyperparameters required by each model, and the best model with its tuning hyperparameters was targeted with the smallest RMSE.

Using the best models (random forest is consistently the best model; Fig. S2 and Fig. S7), we predicted BNPP, the proportional depth distribution (PDD) of BNPP inferred from roots across the globe with gridded driver variables at the resolution of $0.0083^{\circ}(\sim 1 \mathrm{~km}$ at the equator). The BNPP in each soil depth can be finally calculated in BNPP $\times$ PDD. Prediction uncertainty in each $1 \mathrm{~km}$ pixel was quantified using a Monte Carlo approach by randomly drawing 500 individual trees with replacement from the random forest model to predict BNPP, PDD. These 500 estimates were used to calculate the mean $(m)$ and standard deviation $(s d)$ of BNPP and PDD at each of the seven-layer depths. The prediction uncertainty $(\mathrm{U})$ was expressed as the coefficient of variation (CV), i.e., $s d / m$. The total uncertainty of BNPP depth allocation (BNPP $\times$ PDD) was estimated as $U_{\text {total }}=\sqrt{U_{B N P P}^{2}+U_{P D D}^{2}}$.

\section{References}

1. M. L. Imhoff, L. Bounoua, T. Ricketts, C. Loucks, R. Harriss, W. T. Lawrence, Global patterns in human consumption of net primary production. Nature429, 870-873 (2004).

2. F. Krausmann, K. Erb, S. Gingrich, H. Haberl, A. Bondeau, V. Gaube, C. Lauk, C. Plutzar, T. D. Searchinger, Global human appropriation of net primary production doubled in the 20th century. Proc. Natl. Acad. Sci. U. S. A.110, 10324-10329 (2013).

3. J. K. Green, S. I. Seneviratne, A. M. Berg, K. L. Findell, S. Hagemann, D. M. Lawrence, P. Gentine, Large influence of soil moisture on long-term terrestrial carbon uptake. Nature565, 476-479 (2019). 
4. N. H. Batjes, Harmonized soil property values for broad-scale modelling (WISE30sec) with estimates of global soil carbon stocks. Geoderma269, 61-68 (2016).

5. L. Greiner, A. Keller, A. Grêt-Regamey, A. Papritz, Soil function assessment: review of methods for quantifying the contributions of soils to ecosystem services. Land Use Policy69, 224-237 (2017).

6. Z. Luo, G. Wang, E. Wang, Global subsoil organic carbon turnover times dominantly controlled by soil properties rather than climate. Nat. Commun.10, 3688 (2019).

7. Y. Kuzyakov, Priming effects: Interactions between living and dead organic matter. Soil Biol. Biochem.42, 1363-1371 (2010).

8. W. X. Cheng, W. J. Parton, M. A. Gonzalez-Meler, R. Phillips, S. Asao, G. G. McNickle, E. Brzostek, J. D. Jastrow,Synthesis and modeling perspectives of rhizosphere priming. New Phytol.201, 31-44 (2014).

9. Z. Luo, Y. Luo, G. Wang, J. Xia, C. Peng, Warming-induced global soil carbon loss attenuated by downward carbon movement. Glob. Change Biol. 00, 1-13 (2020).

10. E. Garnier, Resource capture, biomass allocation and growth in herbaceous plants. Trend. Ecol. Evol.6, 126-131 (1991).

11. J. W. Raich, K. J. Nadelhoffer, Belowground carbon allocation in forest ecosystems: Global trends. Ecology70, 1346-1354 (1989).

12. E. A. Davidson, K. Savage, P. Bolstad, D. A. Clark, P. S. Curtis, D. S. Ellsworth, P. J. Hanson, B. E. Law, Y. Luo, K. S. Pregitzer, J. C. Randolph, D. Zak, Belowground carbon allocation in forests estimated from litterfall and IRGA-based soil respiration measurements. Agric. For. Meteorol.113, 39-51 (2002).

13. J. Balesdent, I. Basile-Doelsch, J. Chadoeuf, S. Cornu, D. Derrien, Z. Fekiacova, C. Hatté, Atmospheresoil carbon transfer as a function of soil depth. Nature559, 599-602 (2018).

14. N. Fan, S. Koirala, M. Reichstein, M. Thurner, N. Carvalhais, Apparent ecosystem carbon turnover time: uncertainties and robust features. Earth Syst. Sci. Data Discuss.2020, 1-25 (2020).

15. L. A. Gherardi, O. E. Sala, Global patterns and climatic controls of belowground net carbon fixation. Proc. Natl. Acad. Sci. 117, 20038-20043 (2020).

16. Y. Malhi, C. A. J. Girardin, G. R. Goldsmith, C. E. Doughty, N. Salinas, D. B. Metcalfe, H. Huasco, J. E. Silva-Espejo, J. D. Aguilla-Pasquell, F. F. Amézquita, The variation of productivity and its allocation along a tropical elevation gradient: a whole carbon budget perspective. New Phytol.214, 1019-1032 (2017).

17. X. Y. Zhang, W. Wang, The decomposition of fine and coarse roots: their global patterns and controlling factors. Sci. Rep.5, 10 (2015).

18. M. L. McCormack, I. A. Dickie, D. M. Eissenstat, T. J. Fahey, C. W. Fernandez, D. Guo H. Helmisaari, E. A. Hobbie, C. M. Iversen, R. B. Jackson, J. Leppälammi-Kujansuu, R. J. Norby, R. P. Phillips, K. S. Pregitzer, S. G. Pritchard, B. Rewald, M. Zadworny, Redefining fine roots improves understanding of below-ground contributions to terrestrial biosphere processes. New Phytol.207, 505-518 (2015).

19. P. Friedlingstein, P. M. Cox, R. A. Betts, L. Bopp, R. Schnur, Climate-carbon cycle feedback analysis: Results from the (CMIP)-M-4 model intercomparison. J. Clim.19, 3337-3353 (2006). 
20. M. S. Zhao, S. W. Running, Drought-induced reduction in global terrestrial net primary production from 2000 through 2009. Science329, 940-943 (2010).

21. W. Cramer, A. Bondeau, F. I. Woodward, I. C. Prentice, R. A. Betts, V. Brovkin, P. M. Cox, V. Fisher, J. A. Foley, A. D. Friend, C. Kucharik, M. R. Lomas, N. Ramankutty, S. Sitch, B. Smith, A. White, C. YoungMolling, Global response of terrestrial ecosystem structure and function to $\mathrm{CO}_{2}$ and climate change: results from six dynamic global vegetation models. Glob. Change Biol.7, 357-373 (2001).

22. X. Xu, Y. Luo, Z. Shi, X. Zhou, D. Li, Consistent proportional increments in responses of belowground net primary productivity to long-term warming and clipping at various soil depths in a tallgrass prairie. Oecologia174, 1045-1054 (2014).

23. L. López-Mársico, A. Altesor, M. Oyarzabal, P. Baldassini, J. M. Paruelo, Grazing increases belowground biomass and net primary production in a temperate grassland. Plant Soi/392, 155-162 (2015).

24. D. Hertel, G. Moser, H. Culmsee, S. Erasmi, V. Horna, B. Schuldt, Ch. Leuschner, Below- and aboveground biomass and net primary production in a paleotropical natural forest (Sulawesi, Indonesia) as compared to neotropical forests. For. Ecol. Manage.258, 1904-1912 (2009).

25. Y. Fan, G. Miguez-Macho, E. G. Jobbágy, R. B. Jackson, C. Otero-Casal, Hydrologic regulation of plant rooting depth. Proc. Natl. Acad. Sci.114, 10572-10577 (2017).

26. H. Lambers, R. S. Oliveira, in Plant physiological ecology. (Springer, 2019), pp. 187-263.

27. K. Mokany, R. J. Raison, A. S. Prokushkin, Critical analysis of root: shoot ratios in terrestrial biomes. Glob. Change Biol. 12, 84-96 (2006).

28. A. Ledo, K. I. Paul, D. F. R. P. Burslem, J. J. Ewel, C. Barton, M. Battaglia, K. Brooksbank, J. Carter, T. H. Eid, J. R. England, A. Fitzgerald, J. Jonson, M. Mencuccini, K. D. Montagu, G. Montero, W. A. Mugasha, E. Pinkard, S. Roxburgh, C. M. Ryan, R. Ruiz-Peinado, S. Sochacki, A. Specht, D. Wildy, C. Wirth, A. Zerihun, J. Chave, Tree size and climatic water deficit control root to shoot ratio in individual trees globally. New Phytol.217, 8-11 (2018).

29. J. Canadell, R. B. Jackson, J. R. Ehleringer, H. A. Mooney, O. E. Sala, E. D. Schulze, Maximum rooting depth of vegetation types at the global scale. Oecologia108, 583-595 (1996).

30. G. Blume-Werry, A. Milbau, L. M. Teuber, M. Johansson, E. Dorrepaal, Dwelling in the deep-strongly increased root growth and rooting depth enhance plant interactions with thawing permafrost soil. New Phytol.223, 1328-1339 (2019).

31. R. B. Jackson, J. Canadell, J. R. Ehleringer, H. A. Mooney, O. E. Sala, E. D. Schulze, A global analysis of root distributions for terrestrial biomes. Oecologia108, 389-411 (1996).

32. C. A. J. Girardin, Y. Malhi, L. Aragao, M. Mamani, W. H. Huasco, L. Durand, K. J. Feeley, J. Rapp, J. E. Silva-Espejo, M. Silman, N. Salinas, R. J. Whittaker, Net primary productivity allocation and cycling of carbon along a tropical forest elevational transect in the Peruvian Andes. Glob. Change Biol.16, 31763192 (2010).

33. R. A. Gill, R. H. Kelly, W. J. Parton, K. A. Day, R. B. Jackson, J. A. Morgan, J. M. O. Scurlock, L. L. Tieszen, J. V. Castle, D. S. Ojima, X. S. Zhang, Using simple environmental variables to estimate 
below-ground productivity in grasslands. Glob. Ecol.Biogeogr.11, 79-86 (2002).

34. Y. Sun, Y. Yang, X. Zhao, Z. Tang, S. Wang, J. Fang, Global patterns and climatic drivers of above-and belowground net primary productivity in grasslands. Sci. China Life Sci., 1-13 (2020).

35. D. A. Way, R. Oren, Differential responses to changes in growth temperature between trees from different functional groups and biomes: a review and synthesis of data. Tree Physiol.30, 669-688 (2010).

36. D. Wang, S. A. Heckathorn, X. Wang, S. M. Philpott, A meta-analysis of plant physiological and growth responses to temperature and elevated $\mathrm{CO}_{2}$. Oecologia169, 1-13 (2012).

37. E. Whitman, M.-A. Parisien, D. K. Thompson, M. D. Flannigan, Short-interval wildfire and drought overwhelm boreal forest resilience. Sci. Rep.9, 18796 (2019).

38. C. Carcaillet, Y. Bergeron, P. J. H. Richard, B. Fréchette, S. Gauthier, Y. T. Prairie, Change of fire frequency in the eastern Canadian boreal forests during the Holocene: does vegetation composition or climate trigger the fire regime? J. Ecol.89, 930-946 (2001).

39. E. T. Mitchard, The tropical forest carbon cycle and climate change. Nature559, 527-534 (2018).

40. M. D. Walker, C. H. Wahren, R. D. Hollister, G. H. R. Henry, P. A. Wookey, Plant community responses to experimental warming across the tundra biome. Proc. Natl. Acad. Sci.103, 1342-1346 (2006).

41. H. J. van der Kolk, M. M. P. D. Heijmans, J. van Huissteden, J. W. M. Pullens, F. Berendse, Potential Arctic tundra vegetation shifts in response to changing temperature, precipitation and permafrost thaw. Biogeosciences13, 6229-6245 (2016).

42. A. R. Dexter, Soil physical quality: Part I. Theory, effects of soil texture, density, and organic matter, and effects on root growth. Geoderma120, 201-214 (2004).

43. H. R. McCarthy, R. Oren, K. H. Johnsen, A. Gallet-Budynek, S. G. Pritchard, C. W. Cook, S. L. LaDeau, R. B. Jackson, A. C. Finzi, Re-assessment of plant carbon dynamics at the Duke free-air $\mathrm{CO}_{2}$ enrichment site: interactions of atmospheric $\mathrm{CO}_{2}$ with nitrogen and water availability over stand development. New Phytol.185, 514-528 (2010).

44. W. R. Wieder, C. C. Cleveland, W. K. Smith, K. Todd-Brown, Future productivity and carbon storage limited by terrestrial nutrient availability. Nat. Geosci.8, 441-444 (2015).

45. D. A. Clark, S. Brown, D.W. Kicklighter, J.Q. Chambers, J.R. Thomlinson, J. Ni, Measuring net primary production in forests: concepts and field methods. Ecol. Appl.11, 356-370 (2001).

46. D. G. Milchunas, W. K. Lauenroth, Belowground Primary Production by Carbon Isotope Decay and Long-term Root Biomass Dynamics. Ecosystems4, 139-150 (2001).

47. C. Bertin, X. Yang, L. A. Weston, The role of root exudates and allelochemicals in the rhizosphere. Plant soil256, 67-83 (2003).

48. G. T. Freschet, G. T. Freschet, O. J. Valverde-Barrantes, C. M. Tucker, J. M. Craine, M. L. McCormack, C. Violle, F. Fort, C. B. Blackwood, K. R. Urban-Mead, C. M. Iversen, A. Bonis, L. H. Comas, J. H. C. Cornelissen, M. Dong, D. Guo, S. E. Hobbie, R. J. Holdaway, S. W. Kembel, N. Makita, V. G. Onipchenko, C. Picon-Cochard, P. B. Reich, E. G. de la Riva, S. W. Smith, N. A. Soudzilovskaia, M. G. Tjoelker, D. A. 
Wardle, C. Roumet, J. C. Cahill, Climate, soil and plant functional types as drivers of global fine-root trait variation. J. Ecol.105, 1182-1196 (2017).

49. C. L. Quéré, R. M. Andrew, P. Friedlingstein, S. Sitch, D. Zhu, Global Carbon Budget 2017. Earth Syst. Sci. Data10, 405-448 (2018).

50. S. H. Jochen, J. R. B., The global biogeography of roots. Ecol. Monogr.72, 311-328 (2002).

51. S. E. Fick, R. J. Hijmans, WorldClim 2: new 1-km spatial resolution climate surfaces for global land areas. Int. J. Climatol.37, 4302-4315 (2017).

52. J. T. Abatzoglou, S. Z. Dobrowski, S. A. Parks, K. C. Hegewisch, TerraClimate, a high-resolution global dataset of monthly climate and climatic water balance from 1958-2015. Sci. Data5, 170191 (2018).

53. S. Channan, K. Collins, W. Emanuel, Global mosaics of the standard MODIS land cover type data. University of Maryland and the Pacific Northwest National Laboratory, College Park, Maryland, USA30, (2014).

54. D. M. Olson, E. Dinerstein, E. D. Wikramanayake, N. D. Burgess, G. V. N. Powell, E. C. Underwood, J. A. D'amico, I. Itoua, H. E. Strand, J. C. Morrison, C. J. Loucks, T. F. Allnutt, T. H. Ricketts, Y. Kura, J. F. Lamoreux, W. W. Wettengel, P. Hedao, K. R. Kassem, Terrestrial Ecoregions of the World: A New Map of Life on Earth: A new global map of terrestrial ecoregions provides an innovative tool for conserving biodiversity. Bioscience51, 933-938 (2001).

55. R Development Core Team. (R Foundation for Statistical Computing, Vienna, Austria, 2020).

56. O. Conrad, B. Bechtel, M. Bock, H. Dietrich, E. Fischer, L. Gerlitz, J. Wehberg, V. Wichmann, J. Böhner, et al., System for Automated Geoscientific Analyses (SAGA) v. 2.1.4. Geosci. Model Dev.8, 1991-2007 (2015).

\section{Declarations}

Acknowledgments This work is financially supported by the National Natural Science Foundation of China (Grands Nos. 41930754, 41775156, 42001105), the Postdoctoral Science Foundation of China (Grant No. 2020M681872). Z.L. thanks the funding from the Fundamental Research Funds for the Central Universities, Grant No: 2020FZZX001-06, and Research Innovation Foundation for Young Scholars, Grant No: K20200203.

\section{Data and code availability}

All data supporting the findings of this study are available on https://figshare.com/articles/dataset/Datasets_of_NPP_soil_radiocarbon_and_root_biomass/12840050. Code used to generate the results is available from the corresponding author (luozk@zju.edu.cn).

Authors contributions Z.L. conceived the study; G.W., Z.L., J.C., Y.C. compiled the data; G.W., L.X. and Z.L. led the data assessment with the contributions of X.M. and X.G.; L.X. conducted global mapping; Z.L., L.X., G.W., and J.C. interpreted the results with the contribution of all authors; Z.L., L.X., and G.W. led manuscript writing with substantial contributions of all authors. 
Competing interests The authors declare no competing interests.

Figures
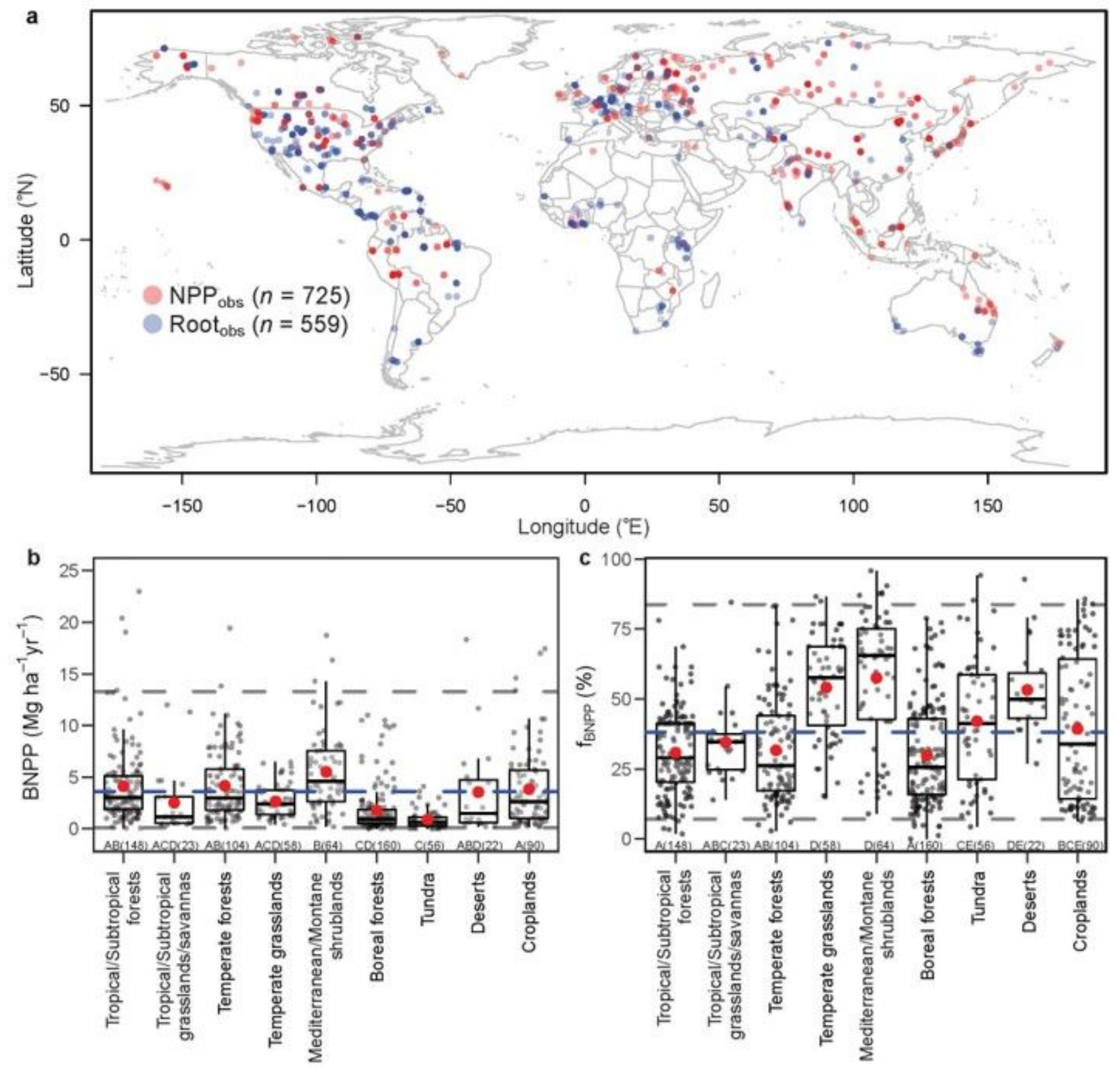

Figure 1

Belowground net primary production (BNPP) and its depth distribution. a, The location of soil profiles with in situ measurements of NPP with its above- and below-ground fractions (NPPobs) and the depth distribution of root biomass (Rootobs). $b$, The distribution of BNPP among nine biomes. (c) The fraction 
of BNPP (fBNPP) relative to total NPP inferred from NPPobs. Boxplots show the median and interquartile range with whiskers extending to 1.5 times of the interquartile range, and red dots show averages.

Different capital letters below the boxes indicate significant difference $(P<0.05)$ among biomes, and numbers in parentheses show sample size. Blue dashed lines show the average, and the upper and lower grey dashed lines show the $97.5 \% 2.5 \%$ quantiles. Note: The designations employed and the presentation of the material on this map do not imply the expression of any opinion whatsoever on the part of Research Square concerning the legal status of any country, territory, city or area or of its authorities, or concerning the delimitation of its frontiers or boundaries. This map has been provided by the authors. 
Percentage depth distribution of BNPP (\%)

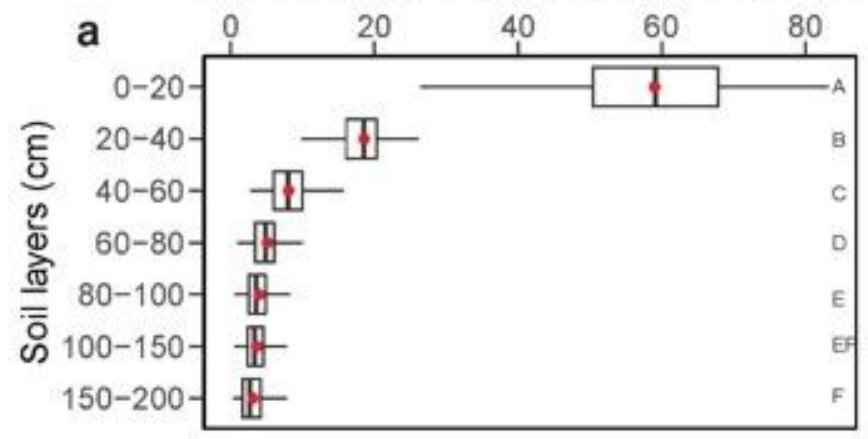

Percentage depth distribution of BNPP (\%)

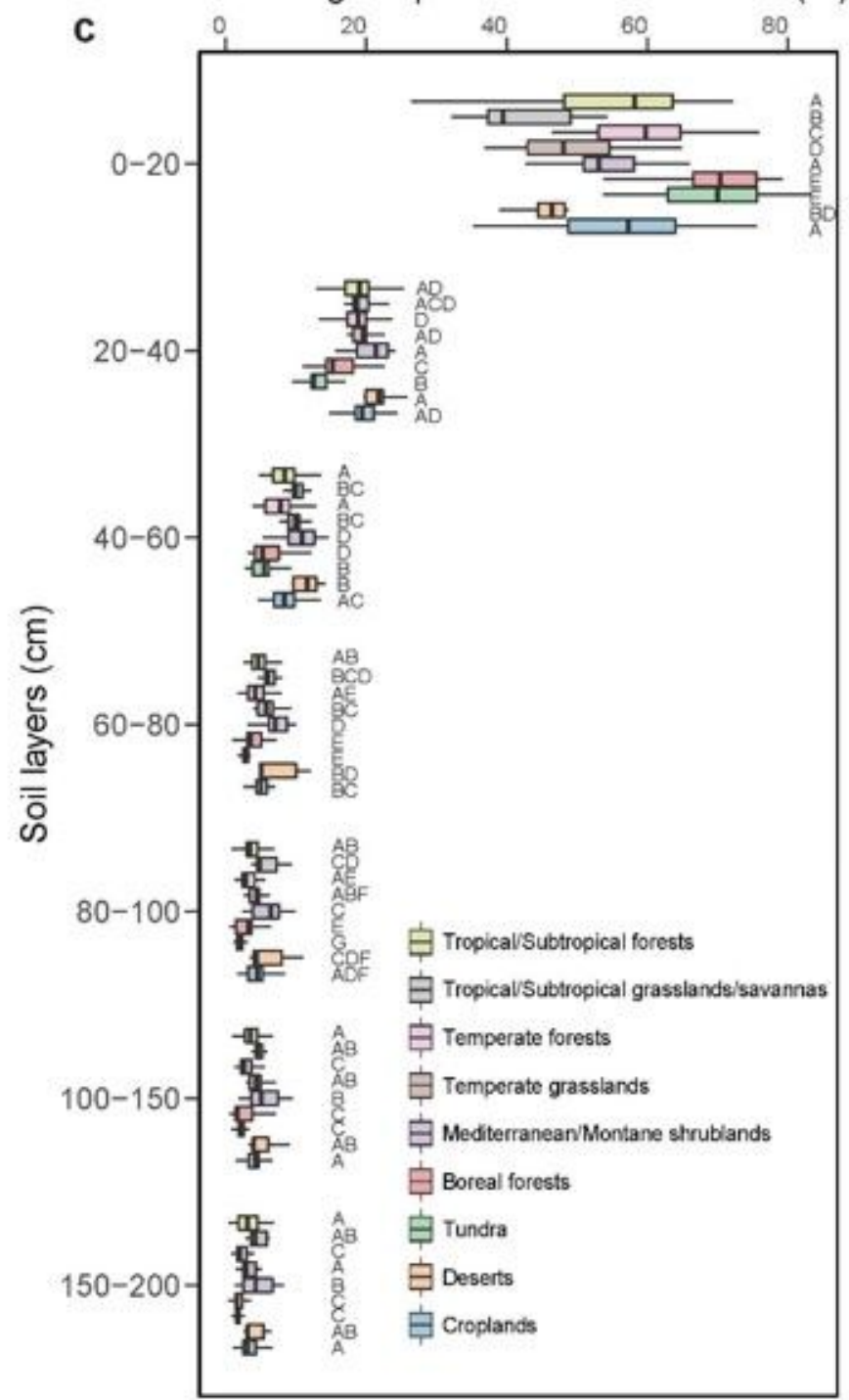

Depth distribution of absolute BNPP ( $\left.\mathrm{Mg} \mathrm{ha}^{-1}\right)$

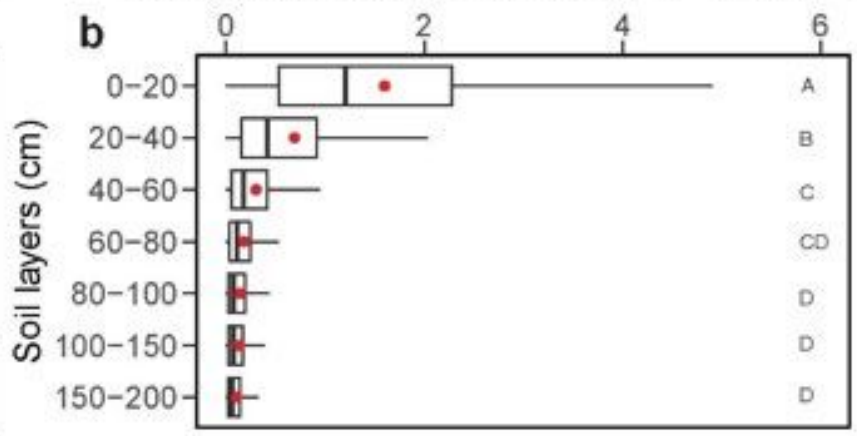

d

Depth distribution of absolute BNPP $\left(\mathrm{Mg} \mathrm{ha}^{-1}\right)$

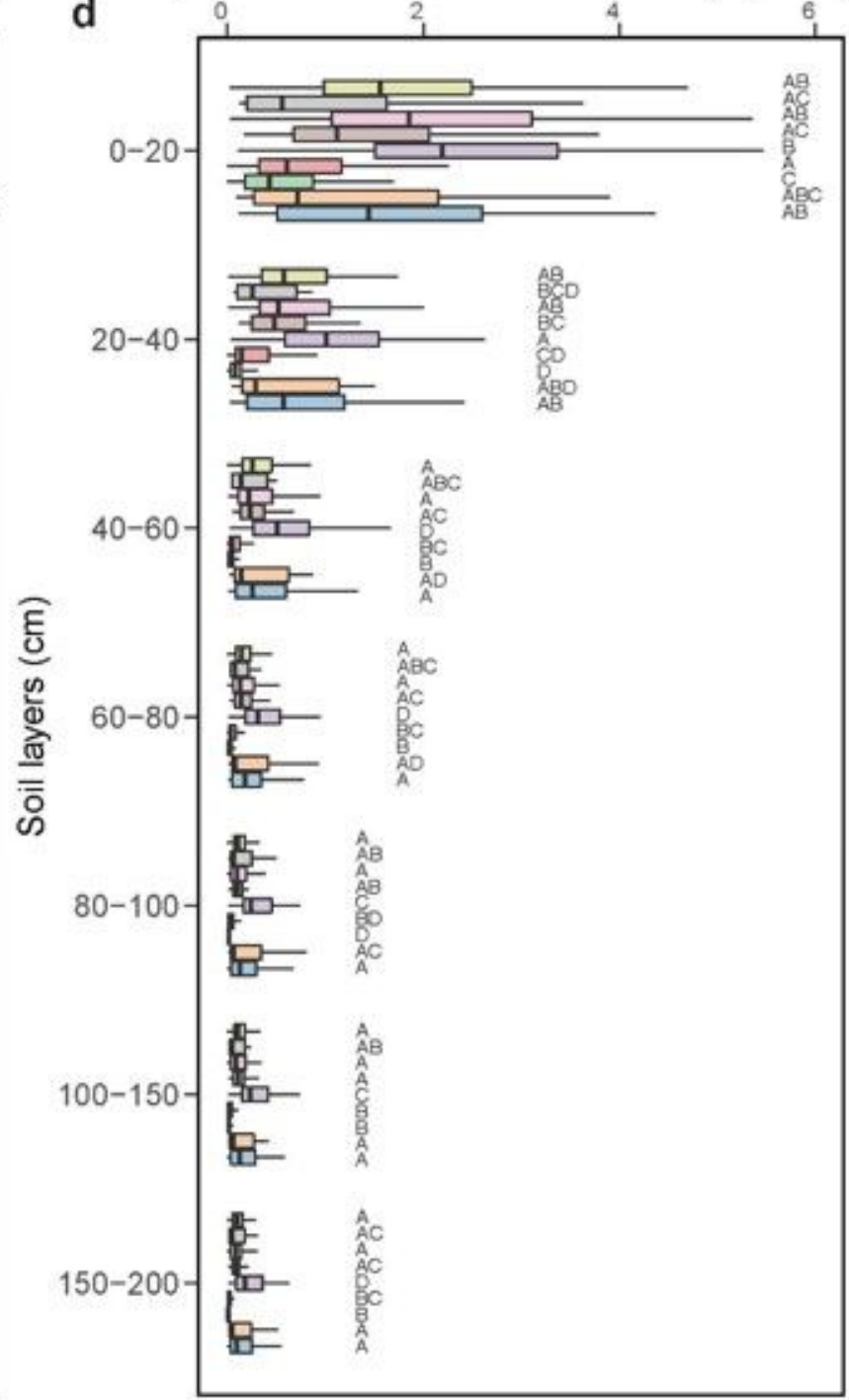

\section{Figure 2}

Depth distribution of belowground net primary production (BNPP). a and c show the observed proportional depth distribution of BNPP across the globe and among biomes, respectively; $b$ and $d$ show the observed depth distribution of absolute BNPP across the globe and among biomes, respectively. Boxplots show the median and interquartile range, with whiskers extending to the most extreme data 
point which is $1.5 \times(75-25 \%)$ data range from the box. Significant differences in the same soil layer among biomes in $\mathrm{c}$ and $\mathrm{d}$ are denoted by different capital letters $(\mathrm{P}<0.05)$.

a

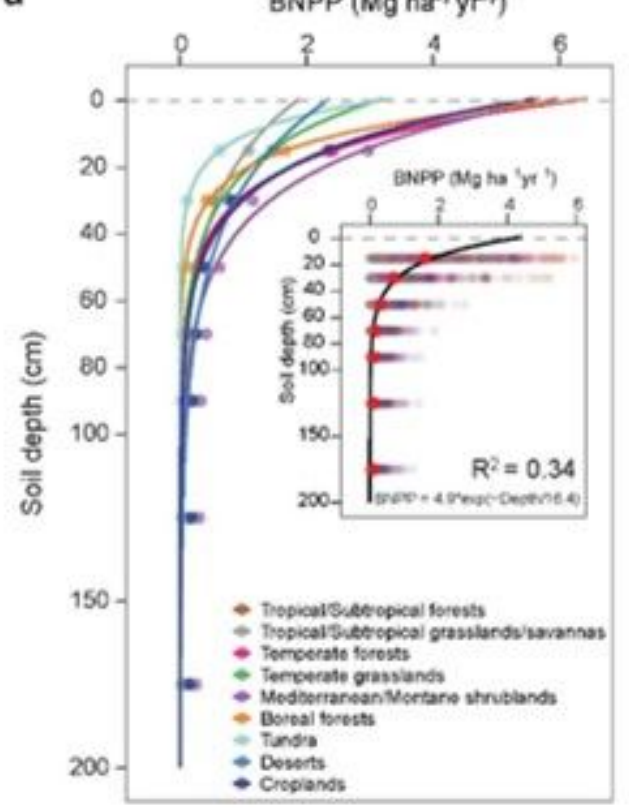

b

Relative importance (\%)

$\left[\begin{array}{l}14 \\ -12 \\ -10 \\ -8 \\ -6 \\ -4 \\ -2 \\ 0\end{array}\right.$

All - Total soil profile

1. $-0.20 \mathrm{~cm}$

2. $20-40 \mathrm{~cm}$

$3.40 .60 \mathrm{~cm}$

$4.60-80 \mathrm{~cm}$

5. $-80-100 \mathrm{~cm}$

$6 \cdot 100.150 \mathrm{~cm}$

$7=150-200 \mathrm{~cm}$

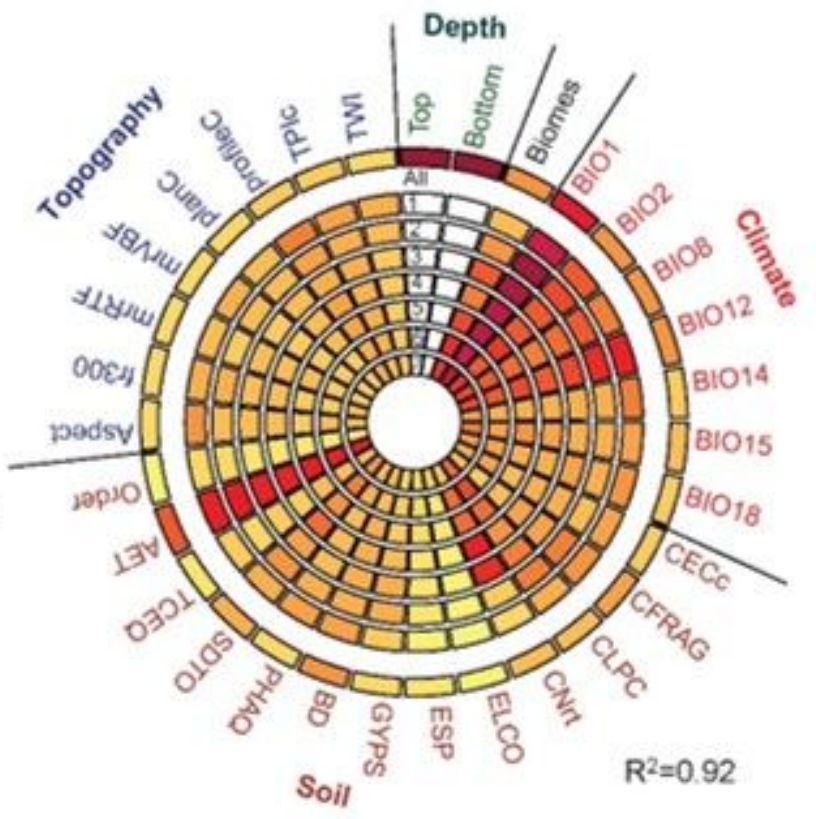

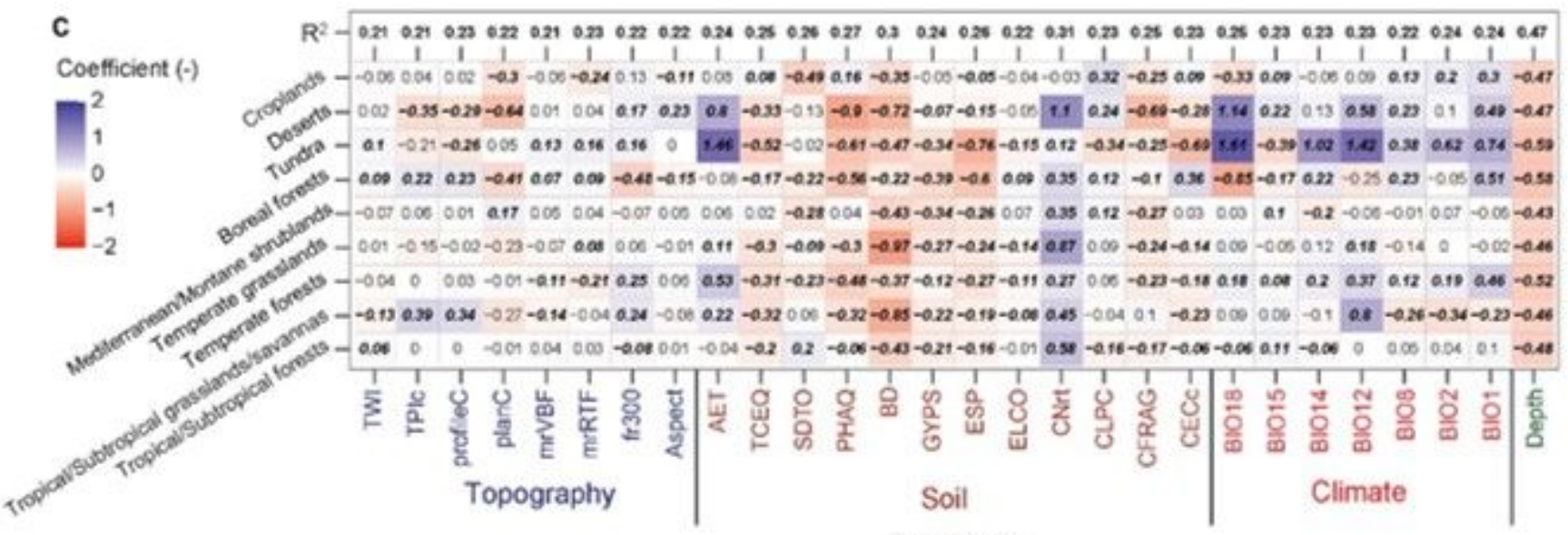

Predictors

Figure 3

Drivers of the depth distribution of belowground net primary production (BNPP). a, BNPP depth distribution in nine biomes predicted as an exponential function of soil depth. Dots show biome-specific average BNPP in soil layer depths, and lines show regression lines. Parameters for the regression lines are shown in Table S3. Inset plot in a shows the relstionship pooling all data together, with red dots show global averages. $b$, the relative importance of environmental factors for predicting BNPP depth distribution using a random forest model. The outer-ring shows results for the whole soil profile, and the seven inner-rings show results for seven soil layer depths, respectively. c, the coefficients of environmental predictors for the linear mixed-effect models for predicting whole soil profile BNPP depth distribution in nine biomes. Intercept is the intercept of the linear mixed-effects models. Bold italic values 
indicate that the coefficients are significant at $P<0.05$, and R2 is the determinant coefficient for the corresponding predictor. See Table S1 for the details of the environmental predictors.
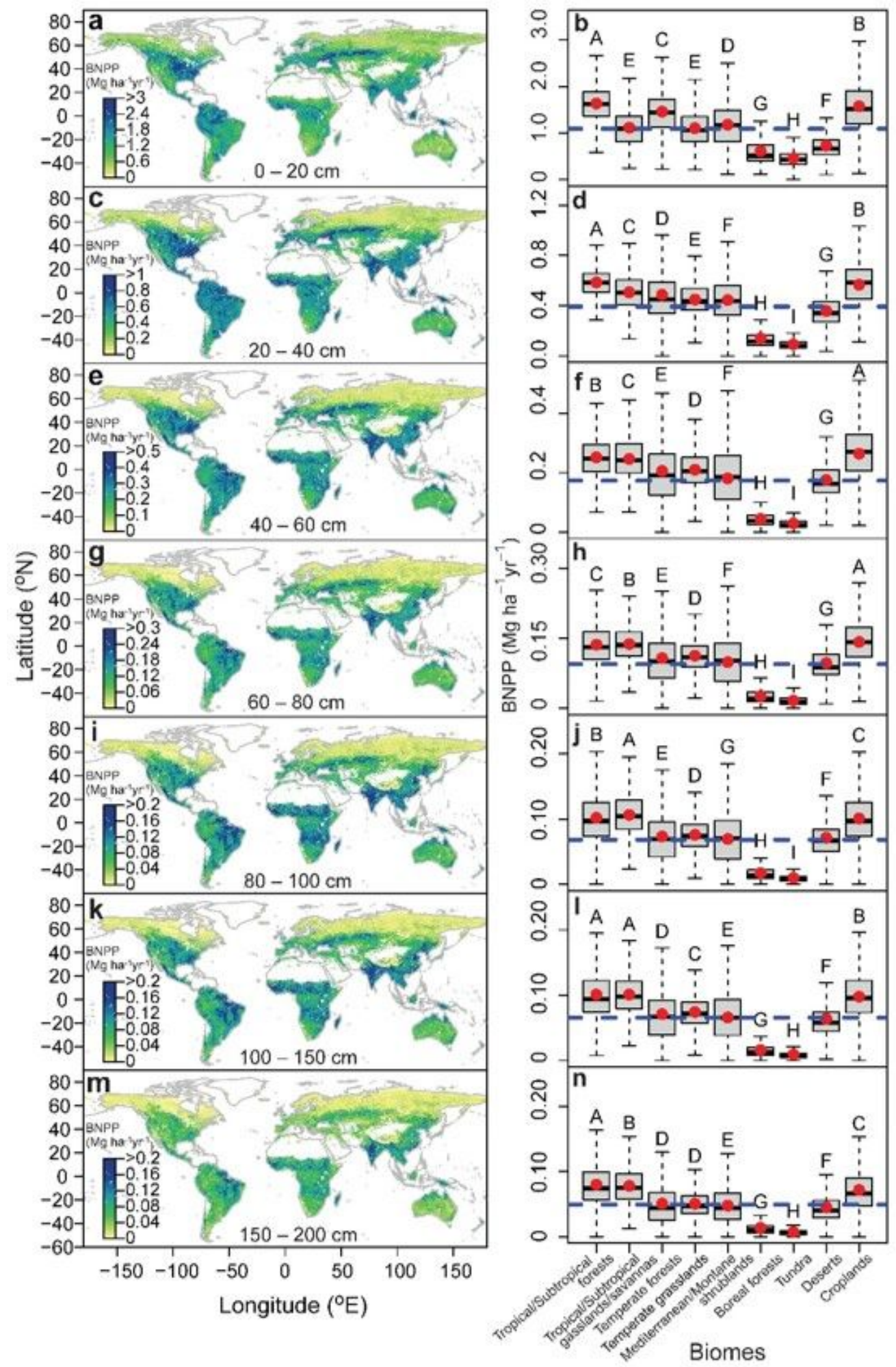

Figure 4

Global pattern of belowground net primary production (BNPP) in seven soil layers (left panel) with the corresponding aggregated BNPP in nine biomes (right panel). Boxplots show the median and interquartile range with whiskers extending to 1.5 times of the interquartile range. Red dots and blue dash lines show 
biome-specific and global averages, respectively. Significant differences of BNPP among biomes in a typical soil layer are denoted by different capital letters $(P<0.05)$. Please note the different scales in different depths. Note: The designations employed and the presentation of the material on this map do not imply the expression of any opinion whatsoever on the part of Research Square concerning the legal status of any country, territory, city or area or of its authorities, or concerning the delimitation of its frontiers or boundaries. This map has been provided by the authors.

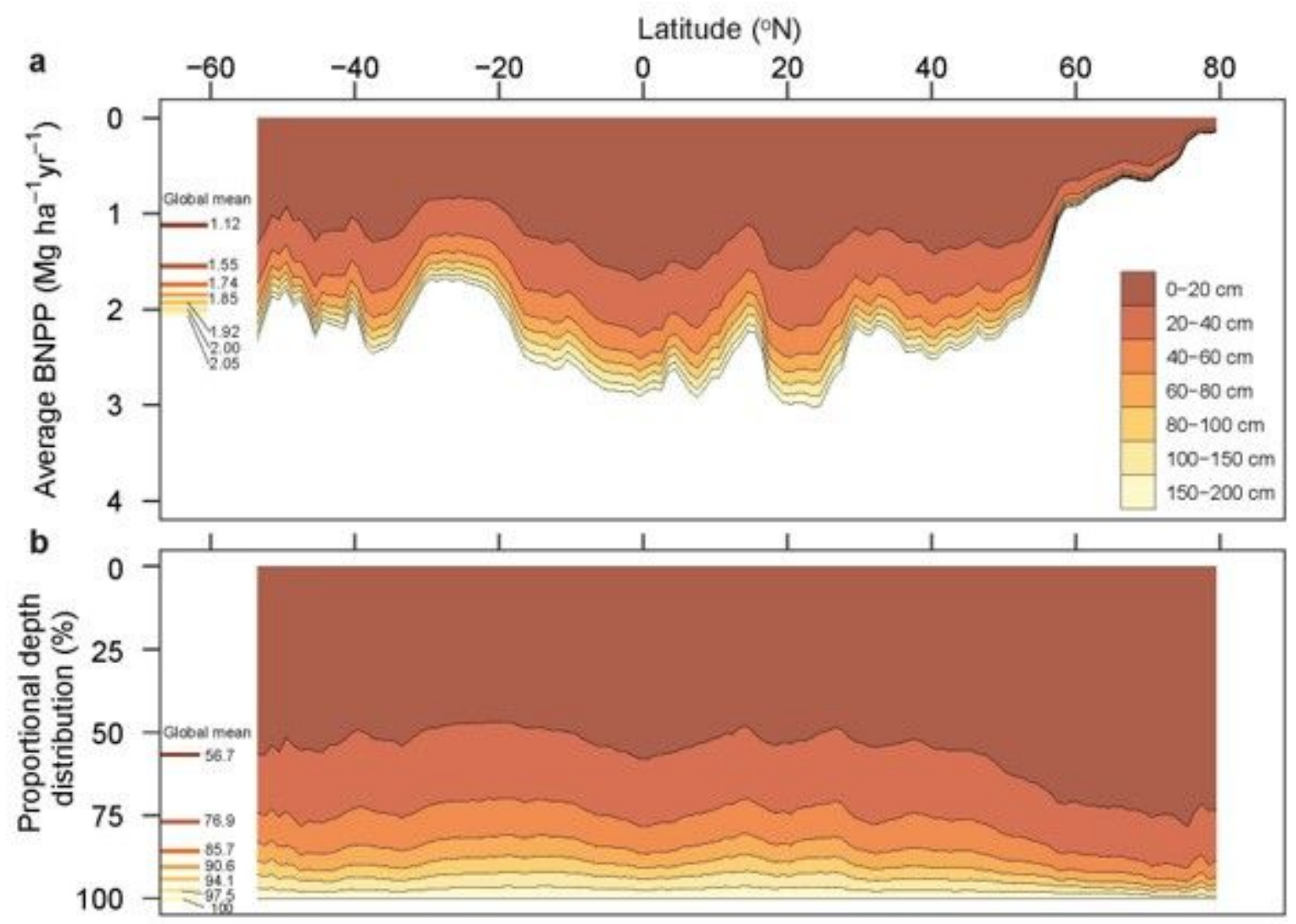

\section{Figure 5}

Latitudinal pattern of belowground net primary production (BNPP). a, depth distribution of absolute BNPP; $b$, proportional depth distribution of BNPP. Both absolute and proportional BNPP were calucated based on aggregated BNPP and its depth distribution in each 1 degree of latitude. Bars and the relevant numbers beside the left y-axes indicate the global cumulative average with increasing soil depths. 

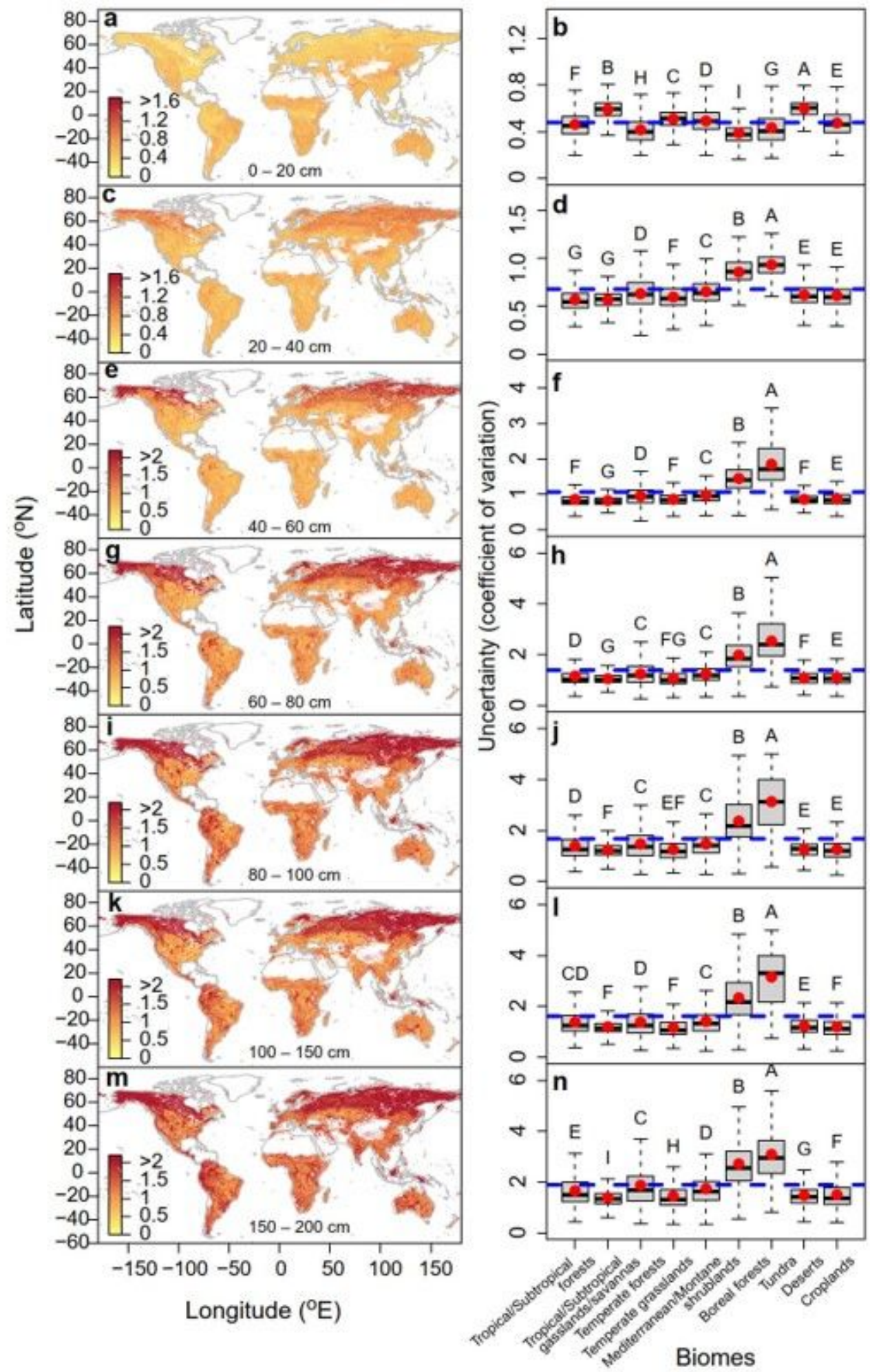

\section{Figure 6}

Global pattern of uncertainties in estimated belowground net primary production in seven soil layers (left panel) with the corresponding uncertainty aggregated to nine biomes (right panel). Uncertainty is estimated as the coefficient of variance in each $0.0083^{\circ}$ grid. Boxplots show the median and interquartile range with whiskers extending to 1.5 times of the interquartile range. Red dots and blue dash lines show biome-specific and global averages, respectively. Significant differences of uncertainties among biomes 
in a typical soil layer are denoted by different capital letters $(P<0.05)$. Note: The designations employed and the presentation of the material on this map do not imply the expression of any opinion whatsoever on the part of Research Square concerning the legal status of any country, territory, city or area or of its authorities, or concerning the delimitation of its frontiers or boundaries. This map has been provided by the authors.

\section{Supplementary Files}

This is a list of supplementary files associated with this preprint. Click to download.

- SupplementaryInformation.docx 